\title{
Ações afirmativas e o princípio da igualdade: cotas raciais, um instrumento social para a promoção da igualdade de oportunidades
}

\section{Affirmative actions and the principle of equality: racial quotas, a social instrument for the promotion of equal opportunities}

Adriana Costa Marinho ${ }^{1}$, Márcia Haydee Porto de Carvalho ${ }^{2}$

\begin{abstract}
RESUMO: As ações afirmativas são políticas públicas ou privadas que têm como objetivo diminuir as desigualdades, no meio social, em prol dos grupos socialmente vulneráveis, ou seja, buscam a concretização da igualdade material, em meio a um cenário de desigualdades e discriminações, ao apresentar-se, como espécie de ações afirmativas, o sistema de cota racial, objeto de grandes debates teóricos. Assim, ao visar a um maior conhecimento sobre a temática, o presente trabalho discorrerá sobre as ações afirmativas, no âmbito brasileiro, e suas implicações para a sociedade. O foco da discussão será o embate sobre a constitucionalidade das ações afirmativas e o sistema de cotas raciais, com base no julgamento da Ação por Descumprimento de Preceito Fundamental (ADPF) $\mathrm{n}^{\mathrm{o}}$ 186. O trabalho fará um breve relato das ações afirmativas e o princípio da igualdade, a partir da análise sobre a igualdade formal e material, sendo a última a justificativa para a constitucionalidade das ações afirmativas. Por fim, fará uma análise das cotas raciais, no Brasil, e apresentará alguns dados relevantes após a vigência da lei de cotas. Para tal estudo, adotou-se uma pesquisa bibliográfica de caráter exploratório.
\end{abstract}

PALAVRAS-CHAVE: Cotas Raciais; Igualdade Material; Ações Afirmativas.

ABSTRACT: Affirmative actions are public or private policies that aim to reduce inequalities in the social environment in favor of socially vulnerable groups, that is, they seek the concretization of material equality, amidst a scenario of inequalities and discriminations, presenting themselves as species of affirmative actions the system of racial quota, object of great theoretical debates. Thus, aiming at a greater knowledge on the subject, the present work will discuss affirmative actions in the Brazilian context and its implications for society. The focus of the discussion will be the clash over the constitutionality of affirmative actions and the system of racial quotas, based on the judgment of the Action for Breach of Basic Precept (ADPF) $n^{\circ} 186$. The paper will give a brief account of affirmative actions and the principle of equality, based on the analysis of formal and material equality, the latter being the justification for the constitutionality of affirmative actions. Finally, we will analyze the racial quotas in Brazil, presenting some relevant data after the validity of the quota law. For this study a bibliographic research of exploratory character was adopted.

KEYWORDS: Racial quotas; Equality Material; Affirmative Actions.

\footnotetext{
${ }^{1}$ Acadêmica do $4^{\circ}$ período do curso de Direito da Universidade Ceuma, integrante do Núcleo de Estudos em Violência e Cidadania (NEVIC), bolsista PIBIC Ceuma.

${ }^{1}$ Professora da Universidade Ceuma e UFMA, atualmente lecionando na graduação em Direto e no Mestrado em Direito e Instituições do Sistema de Justiça. Professora pesquisadora integrante do Núcleo de Estudos em Violência e Cidadania (NEVIC) da Universidade Ceuma. Promotora de Justiça.
} 


\section{INTRODUÇÃO}

Falar a respeito das ações afirmativas, no Brasil, é abordar, principalmente, sobre o sistema de cotas, em especial a cota racial que, desde a sua implantação, tem gerado várias opiniões, que vão desde o debate de quem realmente tem direito de gozar desse benefício, até se elas realmente são necessárias, o que nos leva a entender o que são e qual a importância das ações afirmativas para a sociedade brasileira. Assim, de forma geral, as ações afirmativas podem ser definidas como medidas que visam promover a inclusão, além de buscar uma igualdade e diminuir as desigualdades que afetam, principalmente, grupos socialmente vulneráveis, dentre eles os negros.

O escopo do presente trabalho visa analisar o contexto no qual as ações afirmativas estão inseridas e seus objetivos para a promoção da igualdade material, bem como discutir sobre os critérios utilizados para a inserção social de grupos minoritários, em especial os negros. Destarte, justifica-se a pesquisa pela necessidade de um olhar mais crítico sobre o tema, por causa da sua relevância tanto para a sociedade brasileira quanto para o próprio Direito, devido estar diretamente relacionado a problemas sociais, como: a desigualdade e a discriminação racial.

Para melhor esclarecimento do tema, a pesquisa seguirá a seguinte trajetória: inicialmente, será feita uma análise sobre o conceito de ações afirmativas e seus objetivos, acompanhada de um estudo sobre o princípio da igualdade e a constitucionalidade das ações afirmativas; em seguida, serão analisadas as cotas raciais e sua constitucionalidade diante dos argumentos da Ação de Descumprimento de Preceito Fundamental (ADPF) nº 186; e finaliza-se com uma análise de dados em relação às reservas de vagas em Universidades Públicas, após a vigência da Lei nº 12.711/2012.

\section{AÇÃO AFIRMATIVA E O PRINCÍPIO DA IGUALDADE}

Os Estados Unidos foram o primeiro país a utilizar políticas de ação afirmativa que surgiram com o objetivo de solucionar problemas internos, relacionados à segregação racial sofrida pela população negra. As ações afirmativas foram uma resposta às intensas reivindicações internas que visavam à igualdade de direitos civis e à eliminação das leis segregacionistas vigentes no país. (MENEZES 2001). Uma das principais forças atuantes, nesse contexto, foi o movimento negro que combatia, veementemente, as discriminações contra os negros e lutava a favor da igualdade de direitos para todos.

As ações afirmativas surgiram, a princípio, como medidas para corrigir a discriminação racial; todavia, expandiram-se para outros países, e ganharam novas percepções, passaram a ser utilizadas não apenas em prol dos negros, mas de todos os grupos socialmente vulneráveis na sociedade. Para Mendonça (2008), ação afirmativa é um termo tipicamente norte-americano, mas, 
devido a sua expansão para outras partes do mundo, essas medidas passaram também a ser conhecidas como discriminação positiva ou ação positiva; desde então se revelaram como políticas de grande importância para a integração social e a formação de grupos socialmente marginalizados.

\subsection{Conceitos e objetivos}

As ações afirmativas (AAs), também conhecidas como discriminação positiva, ação positiva, política compensatória, medidas antidiscriminatórias etc., são uma política que busca contribuir para o combate à discriminação, seja de raça, gênero, deficiência, ou qualquer outro tipo de preconceito, presente na sociedade contemporânea. Ações afirmativas são políticas públicas ou privadas, com caráter facultativo ou voluntário, que visam combater qualquer tipo de discriminação presente na sociedade, bem como corrigir ou mitigar atos praticados no passado, mas que, ainda hoje, geram efeitos negativos, ou seja, o essencial das ações afirmativas é concretizar a igualdade de acesso a bens fundamentais para todos na sociedade (GOMES, 2001).

Consideram-se, então, as ações afirmativas como um dos meios para a inclusão social, pois consistem em medidas temporárias, que buscam remediar um passado discriminatório, bem como acelerar o processo de igualdade substantiva para os grupos socialmente vulneráveis, ou seja, as minorias étnicas e raciais, em que estão inclusos todos aqueles que sofreram ou sofrem discriminações na sociedade (PIOVESAN, 2005).

Vale ressaltar que as ações afirmativas trazem consigo a combinação de medidas proibitivas e promocionais; a primeira sendo necessária para a proibição da discriminação e a segunda para incluir os grupos vulneráveis na sociedade. Conforme Piovesan (2005), a criação de medidas, que visa ao combate à discriminação, é fundamental, mas não suficiente para alcançar uma igualdade material, ao não ser apenas a igualdade formal. Por isso, junto com as medidas de proibição, devem estar as medidas promocionais para acelerar o processo da igualdade material que se faz presente nas políticas de ações afirmativas.

Em relação aos objetivos das ações afirmativas, Gomes (2001) ressalta que o escopo principal destas deve ser a concretização da efetiva igualdade de oportunidades, ou seja, aferir a igualdade material ou de resultados a todos que são prejudicados com a ineficácia da igualdade formal reconhecida na lei. Dentre outros objetivos, o supracitado autor classifica os seguintes:

a) "[...] induzir transformações de ordem cultural, pedagógica e psicológica, aptas a subtrair do imaginário coletivo a idéia de supremacia e de subordinação de uma raça em relação a outra, do homem em relação à mulher;

b) [...] não apenas coibir a discriminação do presente, mas sobretudo eliminar os efeitos persistentes (psicológicos, culturais e comportamentais) da discriminação do passado, que tendem a se perpetuar; 
c) [...] a implantação de uma certa diversidade e de uma maior representatividade dos grupos minoritários nos mais diversos domínios de atividade pública e privada (GOMES, 2001, p.11)".

Em síntese, o objetivo das ações afirmativas define-se na redução das desigualdades sociais que afeta, principalmente, a minoria socialmente vulnerável, e que, até então, está sub-representada na sociedade. De forma geral, o objetivo central é a busca da transição da igualdade formal para a concretização da igualdade material, ao se reconhecer as desigualdades existentes no meio social. Portanto, as ações afirmativas objetivam a concretização da igualdade de oportunidade entre os cidadãos e, ao mesmo tempo, uma diminuição nas desigualdades socioeconômicas que assolam o meio social (VILAS-BÔAS, 2003).

\subsubsection{Caráter compensatório e distributivo}

Já se demonstrou que as ações afirmativas são políticas destinadas a promover uma igualdade material, pois diminuem as desigualdades sociais, que afetam os grupos vulneráveis, e, seguindo essa linha de pensamento, elas evidenciam por que essas políticas possuem um caráter compensatório e distributivo.

Na modalidade de justiça compensatória, as ações afirmativas visam à reparação de um dano causado, anteriormente, a um grupo minoritário, como, por exemplo, os negros em face da escravidão. Assim, por meio do reconhecimento das injustiças e diferenças, que esses grupos sofreram, medidas indenizatórias devem ser procuradas para reparar os danos causados, além de que "[...] não podemos considerar essas medidas compensatórias como meramente uma obrigação de mora, posto que muito mais do que isso, já se trata de uma proposta que tem por objetivo as discriminações que ocorreram no passado.” (VILAS-BÔAS, 2014, p. 35)

O caráter distributivo das ações afirmativas está relacionado ao aspecto socioeconômico, que "visa à 'promoção de oportunidades para aqueles que não conseguem se fazer representar de maneira igualitária'.[...]" (NOVELINO, 2014, p. 488), ou seja, objetiva uma distribuição dos benefícios, vantagens e oportunidades, dos bens etc., de forma igualitária para os grupos socialmente vulneráveis, que são indevidamente privados, e têm, como principal objetivo, a efetivação da igualdade material, ao diminuir as desigualdades.

Pode-se perceber que o caráter compensatório está voltado a uma visão do passado, e o caráter distributivo a uma visão do presente, e juntos fazem das ações afirmativas políticas fundamentais para a promoção e a garantia dos direitos de grupos discriminados e que, até então, estavam sub-representados na sociedade. 


\section{AÇÕES AFIRMATIVAS NO BRASIL E O DEBATE JURÍDICO}

No Brasil, a discussão, sobre a ação afirmativa, coincidiu com a luta dos movimentos negros, com o combate à discriminação racial, que perpetuava desde o período escravocrata. Tais movimentos foram de suma importância para a conquista de direitos e mudanças no cenário brasileiro, a respeito das questões raciais e de discriminações, além da conquista de direitos civis. Os movimentos, atuantes na época, passam a exigir do Estado uma postura mais ativa frente às questões de desigualdades e discriminações raciais, ao considerar que, após a abolição da escravatura, os negros não tiveram as mesmas oportunidades e muito menos conseguiram uma posição igualitária, no meio social, como a dos brancos.

Nesse sentido, as ações afirmativas surgem como políticas que visam à efetiva igualdade, motivo que gerou discussões a respeito, principalmente em relação a sua constitucionalidade, que, para alguns, é uma afronta ao princípio da igualdade, justamente por realizar tratamento diferenciado. Para o autor Vilas-Bôas (2003), o ordenamento pátrio brasileiro é perfeitamente compatível com a adoção de políticas de ação afirmativa, pois dá subsídios que permitem a utilização de tais medidas, pois consideram que, para o alcance da igualdade, é necessária a adoção de políticas de ação afirmativa, porque, caso contrário, ela será apenas uma ficção legal. Destarte, o leitor conhecerá o princípio da igualdade e, em seguida, analisará a constitucionalidade das ações afirmativas.

Quando a pesquisa refere-se ao princípio da igualdade, remete-se ao art. $5^{\circ}$, caput da Constituição Federal, que prevê o seguinte "Todos somos iguais perante a lei, sem distinção de qualquer natureza, garantindo-se aos brasileiros e aos estrangeiros residentes no País a inviolabilidade do direito à vida, à liberdade, à igualdade, à segurança e à propriedade, [...]" (BRASIL, 1988). Trata-se de um princípio de suma importância para o ordenamento jurídico e indissociável do sobreprincípio da dignidade da pessoa humana, que define que todos devem ser tratados com igual respeito e consideração, sendo que a igualdade é uma obrigação universal. (NOVELINO, 2014).

Perante o exposto, podem-se citar dois aspectos distintos sob os quais se apresenta o princípio da igualdade, são eles: a igualdade formal e a igualdade material. A igualdade formal se revela como um tratamento isonômico e imparcial a indivíduos que se encontram em uma mesma categoria. (NOVELINO, 2014). Porém, os cidadãos devem ser tratados, de forma igual, de acordo com as suas desigualdades ${ }^{3}$, vedando diferenciações arbitrárias, baseadas em fatos discriminatórios.

\footnotetext{
${ }^{3}$ Tal afirmação é derivada da fórmula proposta por Aristóteles, que visa "tratar igualmente o igual e desigualmente o desigual”. (NOVELINO, 2014, p. 478)
} 
Já ao se tratar da igualdade material, consiste na efetivação substancial do princípio, pois se preocupam com fatores externos, como: classe, natureza da educação recebida etc., nos quais, cada um desses fatores terá impacto sobre o resultado. (GOMES, 2001).

Dessa forma, observa-se que a igualdade material exige do Estado uma postura mais ativa, que passa a reconhecer a diferença existente entre os indivíduos e que tem consigo a intenção de justiça, visto que o desigual passa a ser tratado desigualmente como medida de justiça, ao buscar adotar medidas necessárias para o desenvolvimento e proteção de grupos socialmente vulneráveis. Tal situação pode ser analisada como uma evolução do princípio da igualdade formal para a material, como cita Rocha (1996, p. 288):

Segundo essa nova interpretação, a desigualdade que se pretende e se necessita impedir
para se realizar a igualdade no Direito não pode ser extraída, ou cogitada, apenas no
momento em que se tomam as pessoas postas em dada situação submetida ao Direito, senão
que se deve atentar para a igualdade jurídica a partir da consideração de toda a dinâmica
histórica da sociedade, para que se focalize e se retrate não apenas um instante da vida
social, aprisionada estaticamente e desvinculada da realidade histórica de determinado
grupo social. Há que se ampliar o foco da vida política em sua dinâmica, cobrindo espaço
histórico que se reflita ainda no presente, provocando agora desigualdades nascentes de
preconceitos passados, e não de todo extintos. A discriminação de ontem pode ainda tingir
a pele que se vê de cor diversa da que predomina entre os que detêm direitos e poderes
hoje.

Nota-se que a igualdade material agrega um juízo de valor em relação a igualdades e desigualdades, ao reconhecer a diferença como parte do meio social e que esta requer uma maior atenção por parte do legislador para que a igualdade não se consagre apenas no cunho formal, mas também no material, pois facilita, de determinada forma, a proteção e a defesa dos cidadãos socialmente vulneráveis.

Sendo assim, é na busca pela efetivação da igualdade material que se situam as ações afirmativas, como medidas que visam acelerar o processo da igualdade material, em prol das minorias. Portanto, entende-se que o princípio da igualdade material impõe que poderes públicos adotem medidas voltadas para a redução das desigualdades de recursos ou acesso aos bens na sociedade (NOVELINO, 2014).

Podem-se verificar, em alguns artigos da Constituição Federal, determinações que são típicas de ações afirmativas, como: a previsão da proteção do mercado de trabalho das mulheres $\left(\mathrm{CF}\right.$, art. $\left.7^{\circ}, \mathrm{XX}\right)$, normas relativas ao acesso do portador de deficiência ao mercado de trabalho (CF, art. 37, VIII), e que visam reduzir as desigualdades no âmbito regional (art.43), dentre outras. Logo, são medidas que endossam a legitimidade das ações afirmativas no ordenamento jurídico brasileiro, o que significa dizer que "O Direito Constitucional vigente, no Brasil, é perfeitamente 
compatível com o princípio da ação afirmativa. Melhor dizendo, o Direito brasileiro já contempla algumas modalidades de ação afirmativa, inclusive em sede constitucional” (GOMES, 2001, p. 15).

Com a aplicação das ações afirmativas, o Estado trata de forma igual os iguais, e de forma desigual os desiguais, o que, de certa forma, acaba por ser uma discriminação, só que uma discriminação positiva, que tem o objetivo de mitigar as desigualdades socioeconômicas. Destarte, o ditame constitucional, em algumas situações, admite o tratamento desigual pelos motivos de raça, sexo etc., com medidas que não se apresentam como desrespeito ao princípio da igualdade, mas desde que esse tratamento desigual não se torne fator de desigualdades injustificáveis racionalmente (BANDEIRA DE MELO, 1995).

Percebe-se que as ações afirmativas não violam o princípio da igualdade pelo fato de apresentar um tratamento diferenciado a determinados grupos da sociedade, sendo este tratamento fundamental para se atingir a igualdade material. Portanto, para a correção das desigualdades e promoção dos objetivos fundamentais, contidos na Constituição, deve-se passar por três estágios: a igualdade perante a lei; a previsão da criminalização pelas práticas discriminatórias; e as ações afirmativas. Eis que tentar dizer não para as ações afirmativas é continuar neutro diante das questões de desigualdades. (SILVA HAAS, 2008, Concurso ESMPU).

\subsection{Cotas Raciais e suas implicações para a sociedade}

As ações afirmativas são um universo e diversas são as suas modalidades. No Brasil, elas têm se reduzido à questão das cotas, que é uma espécie de ação afirmativa, pois representa uma das espécies mais criticadas, no contexto brasileiro, quando se trata das cotas destinadas a negros para o ingresso na universidade, devido aos critérios que são utilizados para definir quem deve ser beneficiado com tal sistema.

Para Novelino (2014, p.486), “O sistema de cotas ('reserva de vagas') é apenas um dos mecanismos de proteção de minorias hipossuficientes, ao lado de vários outros, tais como bolsas de estudos, reforço escolar, programas especiais de treinamentos, [...] (grifo do autor)". Por meio das cotas, é feita uma reserva de um determinado número de vagas aos sujeitos que pertencem a um grupo desfavorecido, seja no emprego, seja no ensino.

No Brasil, as cotas contemplam vários setores sociais, como: os índios, as pessoas com deficiência física, as mulheres e os negros. No entanto, a utilização de cotas provoca duras críticas, principalmente quando os beneficiários são os negros, no âmbito educacional, pois é reservado um determinado percentual de vagas para ingresso dessa minoria vulnerável socialmente, justificado 
pelo processo de exclusão e discriminação. Ao considerar-se o cenário da educação brasileira, o acesso à educação nunca foi de forma igual para todos, na sociedade, e os negros sempre foram os maiores prejudicados, conforme mostra o trecho seguinte:

Esta é, pois, a chave para se entender por que existem tão poucos negros nas universidades públicas brasileiras, e quase nenhum nos cursos de maior prestígio e demanda: os recursos públicos são canalizados massivamente para as classes mais afluentes, restando aos pobres (que são majoritariamente negros) “as migalhas” do sistema. (GOMES,2001, p. 14)

Concorda-se que a educação no Brasil, embora seja um dos objetivos a serem alcançados pelo Estado, de fato não é igual para todos, sendo oferecida de forma desigual para a sociedade e os negros são os mais prejudicados, pois são eles a minoria nas universidades e nos cargos de maior prestigio e remuneração. Portanto, nessas perspectivas, as cotas ganham um caráter de política de inclusão social em face dos desfavorecidos socialmente: os "negros".

As cotas raciais, em síntese, são uma oportunidade para o negro ingressar no ensino superior, porque considera-se essa medida como uma efetivação do direito à educação. A finalidade das cotas raciais é a melhoria do estado socioeconômico e o resgate da dívida social para com os negros, visto que aquela visa a um progresso econômico, que os tire da zona de baixa pobreza, e este se refere ao pagamento de uma indenização, devido à reparação aos prejuízos advindos da escravidão. (SILVA HAAS, 2008, Concurso ESMPU).

\subsubsection{ADPF 186: apresentação dos argumentos contrários e favoráveis}

A questão das cotas, para o acesso do negro à universidade, é alvo de grandes discussões, até mesmo dentro do judiciário, que envolvem opiniões contrárias e favoráveis. Uma das ações mais polêmicas, e que, em suma, serviu para consolidar a constitucionalidade das cotas raciais, foi a Arguição de Descumprimento de Preceito Fundamental (ADPF) $n^{\circ}$ 186, proposta pelo Partido Democrata (DEM), que pedia a inconstitucionalidade da política de cotas raciais, adotada pela Universidade de Brasília (UNB).

Como principal argumento, em contraposição às cotas raciais, a ADPF trouxe, em síntese, que os critérios adotados pela UNB, no sistema de cotas, violam os preceitos fundamentais, e, por si, acabam por criar um "Tribunal Racial”, visto que as pessoas são obrigadas a se identificar em uma determinada raça, sendo esta uma política racialista, que não se adéqua ao Brasil, devido a sua mestiçagem. Nessa perspectiva, o que se discute, na supracitada ação, é o sistema de cotas baseado na raça e se tal sistema é realmente necessário. 
A seguir, observam-se os argumentos, que violam os preceitos fundamentais, expostos na ação proposta pelo partido DEM:

[...] a) "pretende demonstrar que a adoção de políticas afirmativas racialistas não é necessária no país (...); b) o conceito de minoria apta a ensejar uma ação positiva estatal difere em cada país. Depende da análise de valores históricos, culturais, sociais, econômicos, políticos e jurídicos de cada povo (..); c) discute tão somente a constitucionalidade da implementação, no Brasil, de ações afirmativas baseadas na raça (...); d) ninguém é excluído, no Brasil, pelo simples fato de ser negro (...); e) cotas para negros nas universidades geram a consciência estatal de raça, promovem a ofensa arbitrária ao princípio da igualdade, gerando discriminação reversa em relação aos brancos pobres, além de favorecerem a classe média negra" (Acórdão, p. 4)

O partido defende que a raça, isoladamente, não pode ser critério legítimo de diferenciação entre o exercício de direitos entre os cidadãos, visto que, diferente dos EUA, onde as questões raciais são mais marcantes, no Brasil, o problema da exclusão social decorre das precárias condições econômicas do país. Assim, o uso das cotas raciais não resolve a exclusão dos negros, mas apenas disfarça a situação de discriminação, além de correr o risco de se criar uma discriminação inversa de brancos pobres.

Perante o exposto, a ação, movida pelo DEM, se posiciona contra as cotas raciais instituídas pela UNB, ao considerar que estas violam os princípios constitucionais, dentre eles o princípio da igualdade, no que concerne à utilização da raça como critério diferenciador dos direitos entre os cidadãos, ao defender que, na realidade, o problema do não acesso do negro à universidade está na condição econômica, que afeta não somente os negros, mas também os brancos, e o uso das cotas sociais seriam suficientes para tal objetivo.

Em defesa das cotas raciais e ao julgar improcedente a ADPF 186, o relator, ministro Ricardo Lewandowski, apresentou seu voto em dez etapas: a primeira sobre o princípio da igualdade, ao destacar a igualdade material e formal; a segunda relacionada à justiça distributiva; a terceira trata sobre as ações afirmativas de acordo com a temática em discussão; a quarta aborda os critérios jurídicos, adotados no Brasil, para ingresso no Ensino Superior e a consciência étnicoracial como fator de exclusão; a quinta ressalta o papel integrador da universidade; a sexta faz abordagens sobre as ações afirmativas nos EUA; a sétima aborda a questão do hétero e a autoidentificação; a oitava faz análise da questão de reserva de vagas ou estabelecimento de cotas; a nona analisa a transitoriedade das políticas das ações afirmativas; e, por fim, a décima discorre sobre a proporcionalidade entre meios e fins. 
Após a abordagem dos supracitados assuntos, o relator conclui o seguinte sobre o uso das cotas raciais na universidade:

(i) têm como objetivo estabelecer um ambiente acadêmico plural e diversificado, superando distorções sociais historicamente consolidadas, (ii) revelam proporcionalidade e a razoabilidade no concernente aos meios empregados e aos fins perseguidos, (iii) são transitórias e preveem a revisão periódica de seus resultados, e (iv) empregam métodos seletivos eficazes e compatíveis com o princípio da dignidade humana, [...] (Acórdão, p.92)

Dessa forma, o ministro Ricardo Lewandowski defendeu que as cotas étnico-raciais são fundamentais para a efetivação do princípio da igualdade que define: "todos são iguais perante a lei", ao diversificar o ambiente acadêmico que é composto tanto por brancos quanto por negros. Por isso, desconsiderar o uso das cotas é deixar de assegurar a igualdade material que, para ele, se faz por intermédio das ações afirmativas. Nesse ambiente, superar as desigualdades é de suma importância para que se tenha a intervenção do Estado que deve analisar essas questões, também, sob a perspectiva da igualdade material. Assim, verifica-se que o principal argumento, que sustenta a constitucionalidade do sistema de cotas, é um dos princípios basilares do Estado Democrático de Direito, o princípio da igualdade material.

Portanto, os principais argumentos expostos, neste trabalho, foram fundamentais para a decisão de improcedência da ADPF 186 e para sustentar a constitucionalidade das cotas raciais. Assim, ficou claro que a busca pela igualdade é um dever ético-jurídico e tem como principal objetivo combater a discriminação existente na sociedade, e este não se faz tão somente no âmbito da igualdade formal, mas sim junto com a igualdade material. Por isso, ser a favor das cotas raciais é reconhecer que as desigualdades existem e que precisa de meios que possam garantir aos desfavorecidos a oportunidade de vida digna. Sendo assim, o fundamento basilar para um Estado Democrático de Direito é promover a igualdade material que se perfaz com o uso de políticas de ações afirmativas, dentre elas, o sistema de cotas raciais.

\subsubsection{Lei de cotas 12.711/2012: mais oportunidades para o ingresso de negros no Ensino Superior}

Em 2012, as cotas passaram a ser obrigatórias para as universidades federais brasileiras, e foram reguladas pela Lei de Cotas $n^{\circ} 12.711$ que foi publicada e entrou em vigor em 29 agosto de 2012. Antes da aprovação da supracitada Lei, algumas universidades já utilizavam o sistema de cotas, mas sem terem uma quantidade fixa de vagas reservadas; isso não condizia com o percentual de inscritos no vestibular, pertencente ao grupo de beneficiários, o que tinha como consequência um baixo número de vagas efetivamente reservadas. (FERES e DAFLON, 2013) 
Assim, a partir da publicação da Lei de Cotas, as universidades federais passaram a adotar os critérios da nova lei, sendo reservadas $50 \%$ das vagas por curso e turno destas instituições para alunos egressos de escolas públicas; alunos de escola pública e baixa renda; alunos pretos, pardos e indígenas de escolas públicas e baixa renda, enquanto os demais $50 \%$ das vagas foram destinados para a ampla concorrência (BRASIL, 2012).

De acordo com o Ministério da Educação, 50\% das vagas reservadas serão subdivididas, sendo metade para estudantes de escolas públicas, com renda familiar bruta igual ou inferior a um salário mínimo e meio per capita, e metade para estudantes de escolas públicas com renda familiar superior a um salário mínimo e meio. Em ambos os casos, também, será levado em conta o percentual mínimo correspondente ao da soma de pretos, pardos e indígenas no estado, de acordo com o último censo demográfico do Instituto Brasileiro de Geografia e Estatística (IBGE). Nesse caso, o cálculo percentual dessas vagas é estabelecido conforme os dados do IBGE, definidos pela composição de cor da população de cada estado, ou seja, as vagas são definidas de acordo com a quantidade de negros, pardos e indígenas autodeclarados. ${ }^{4}$

$\mathrm{O}$ artigo $8^{\circ}$, da supracitada lei, define que, a cada ano, as universidades deveriam implementar cerca de $25 \%$ (vinte e cinco por cento) da quantidade de vagas previstas na lei, tendo estas o prazo máximo de 4 (quatro) anos, após a vigência da lei, para o cumprimento integral das vagas previstas (BRASIL, 2012). Assim, acredita-se que, como efeito, o número de vagas, destinadas aos negros e ocupadas por eles, tenha aumentado com o passar dos anos.

Destarte, o efeito principal, como a obrigatoriedade do sistema de cotas raciais no ensino superior, é o "da correção das distorções e assimetrias na igualdade de oportunidades, do aumento da diversidade e da representação dos afrodescendentes no ambiente universitário e, consequentemente, um ambiente propício à redução dos comportamentos discriminatórios." (IENSUE, 2009, p. 259). Nesse ambiente, observam-se alguns dados, a seguir, em relação ao ingresso dos negros nas universidades após a implementação da lei de cotas.

Um dos principais diagnósticos, advindos da imposição legal do sistema de cotas, é a adesão pelas universidades, pois, conforme revela o Instituto de Pesquisa Econômica Aplicada (Ipea), até 2012, antes da implementação da Lei de Cotas, que tornou a reserva de 50\% das vagas obrigatória, conforme analisado, anteriormente, apenas 23 das 59 universidades federais usavam modalidades de ações afirmativas com recorte social, e após a obrigatoriedade, advinda com a Lei,

\footnotetext{
${ }^{4}$ Informações disponíveis no portal do MEC: http://portal.mec.gov.br/cotas/sobre-sistema.html
} 
houve uma mudança significativa, visto que, no ano de 2013, 100\% das universidades federais já adotavam o sistema de cotas com recorte social/racial. (IPEA, 2015)

Outra mudança significativa, desde a vigência da Lei de Cotas, foi em relação à quantidade de vagas reservadas e sua distribuição. A tabela a seguir, elaborada pelo Grupo de Estudos Multidisciplinares da Ação Afirmativa (Gemma), faz uma pequena análise dos dados em relação ao total de vagas reservadas para beneficiários de baixa renda e PPI (pretos, pardos e índios) nos anos de 2012 e 2015.

Tabela 01- Vagas reservadas pela Lei de Cotas em universidades federais (2012 e 2015)

\begin{tabular}{|l|c|c|}
\hline \multicolumn{1}{|c|}{ Vagas } & Ano 2012 & Ano 2015 \\
\hline Total de Vagas & 140303 & 247940 \\
\hline Vagas Reservadas & 30264 & 115581 \\
\hline Recorte Social & 16677 & 43016 \\
\hline Recorte Racial & 13392 & 67123 \\
\hline
\end{tabular}

Fonte: GEMAA / IESP-UERJ(EURÍSTENES, FERES JÚNIOR, CAMPOS, 2016)

Observa-se que, em relação a reservas de vagas com recorte social, houve um aumento significativo do ano de 2012 a 2015, que duplicou a quantidade de vagas com recorte racial, pois favoreceu a categoria PPI (pretos, pardos e índios). Por meio do supracitado levantamento, é possível ainda analisar o aumento das vagas destinadas aos negros nas universidades federais, pois busca atingir um dos objetivos da Lei de Cotas, ao aumentar a oportunidade de representatividade desse grupo vulnerável, nas universidades, de modo a torná-la mais diversificada e, consequentemente, alcançar efeitos positivos em relação a comportamentos discriminatórios.

Recentemente, a Secretaria Especial de Políticas de Promoção da Igualdade Racial (Seppir) também divulgou informações a respeito do acesso de negros, nas universidades federais, por meio da Lei de Cotas, segundo as quais:

Entre 2013 e 2015, a política afirmativa de reserva de cotas garantiu o acesso a aproximadamente 150 mil estudantes negros em instituições de ensino superior em todo o país. Segundo dados do Ministério da Educação, em 1997 o percentual de jovens negros, entre 18 e 24 anos, que cursavam ou haviam concluído o ensino superior era de $1,8 \%$ e o de pardos, 2,2\%. Em 2013 esses percentuais já haviam subido para 8,8\% e 11\%, respectivamente ${ }^{5}$.

\footnotetext{
${ }^{5}$ A SEPPIR tem como objetivo a formulação, coordenação e articulação de políticas e diretrizes para a promoção da igualdade racial, bem como a formulação, coordenação e avaliação das políticas públicas afirmativas de promoção da igualdade e da proteção dos direitos de indivíduos e grupos étnicos, com ênfase na população negra, afetados por discriminação racial e demais formas de intolerância. (informações disponíveis em : http://www.seppir.gov.br/sobre-aseppir/a-secretaria.
} 
Assim, verificou-se que um dos principais objetivos da Lei de Cotas está sendo alcançado, que é, justamente, aumentar a representatividade dos negros no meio universitário, e tal resultado é fruto do cumprimento da Lei pelas instituições federais de ensino superior. Assim considerou-se que um dos primeiros efeitos, em busca de uma real efetividade da Lei, é possibilitar o acesso de grupos vulneráveis à universidade em busca de igualdade de oportunidades.

Constatou-se que a Lei de Cotas abriu portas para muitos negros em relação ao acesso à universidade; no entanto, ainda, existem várias questões que devem ser consideradas para garantir a verdadeira eficácia dessa Lei para que ela possa ter seus efeitos desejados. Dentre elas, destaca-se a questão se, de fato, as vagas estão sendo preenchidas por quem realmente tem direito; eis que, nesse sentido, um dos critérios para se ter direito ao sistema de cotas é questionado: a autodeclaração, que vem sendo alvo de fraudes no referido sistema.

\section{CONCLUSÃO}

Verificou-se, com o supracitado estudo, que, em uma sociedade diversificada como a brasileira, não se deve deixar de lado as desigualdades existentes no meio social. Assim, quando se refere ao princípio constitucional da igualdade, não se pode fazer uma interpretação isolada, que figura-se apenas na perspectiva formal, mas, também, tem-se que interpretá-lo sobre a perspectiva material, pois é, justamente, por meio da igualdade material, que as pessoas reconhecem as desigualdades que prejudicaram grupos minoritários e os colocaram em desvantagens em determinados segmentos da sociedade.

Assim, as ações afirmativas apresentam-se como políticas que visam corrigir os problemas relacionados às desigualdades que afetam, principalmente, os grupos socialmente vulneráveis, tendo como principal objetivo promover a igualdade material e a erradicação da discriminação. Hoje, não sendo mais questionadas sobre a constitucionalidade, percebe-se que as ações afirmativas são utilizadas em vários segmentos da sociedade, seja em prol dos negros, seja das mulheres, dos índios, dos portadores de deficiência etc.

As cotas raciais foram, em suma, uma das medidas de ações afirmativas mais questionadas quanto a sua constitucionalidade e a sua utilização no meio universitário. A decisão do STF sobre a improcedência da ADPF 186, a respeito dessa questão, representa um avanço significativo para o direito, pois passa a reconhecer que o uso das cotas raciais é necessário para garantir oportunidades 
a grupos que estiveram excluídos, sendo uma justiça distributiva em prol daqueles que são subrepresentados. Assim, a constitucionalidade das cotas raciais foi justificada, principalmente, pela necessidade de garantir, efetivamente, a igualdade material para que todos, sem discriminações, tenham seus direitos de maneira justa, com as mesmas oportunidades.

Desse modo, conclui-se que o sistema de cotas raciais é necessário para mudar o cenário de desigualdade existente entre negros e brancos no universo acadêmico, ao contribuir para um ambiente diversificado. A Lei de Cotas n 12.711/2012 trouxe significativas mudanças em relação à quantidade de vagas reservadas, principalmente para os negros, ao considerar, também, a adesão de $100 \%$ das universidades federais com o objetivo da inclusão racial. No entanto, ressalta-se que somente o uso das cotas não será a solução para as questões aqui relatadas, pois, além do uso do supracitado sistema, também, deve-se haver um acompanhamento para se verificar se, de fato, as vagas reservadas estão sendo ocupadas pelos beneficiários correspondentes.

\section{REFERÊNCIAS}

BANDEIRA DE MELO, Celso Antônio. O conteúdo jurídico do princípio da igualdade. 3. ed. São Paulo: Malheiros Editores, 1995.

BRASIL. Constituição (1988). Constituição da República Federativa do Brasil. Brasília, DF: Senado Federal, 1988.

Lei no 12.711, de 29 de agosto de 2012. Dispõe sobre o ingresso nas universidades federais e nas instituições federais de ensino técnico de nível médio e dá outras providências. Brasília: Congresso Nacional, 2012. Disponível em: < http://www.planalto.gov.br/ccivil_03/_ato20112014/2012/lei/l12711.htm>

Acórdão da ADPF $\mathrm{n}^{\mathrm{o}}$ 186. 2012. Disponível em:

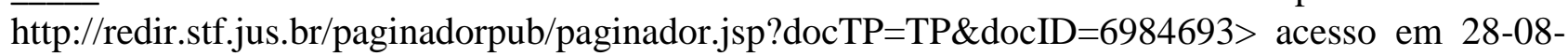
2017.

Concurso ESMPU de Monografias - 2008: POLÍTICA DE COTAS: MITIGAÇÃO DA ISONOMIA EM AÇÃO AFIRMATIVA?- Brasília: Escola Superior do Ministério Público da União, 2009.

EURÍSTENES, Poema; FERES JÚNIOR, João ; CAMPOS, Luiz Augusto. Evolução da Lei $\mathbf{n}^{\circ}$ 12.711 nas universidades federais (2015). Levantamento das políticas de ação afirmativa (GEMAA), IESP-UERJ, dezembro, 2016, pp. 1-25. Disponível em: $<$ http://gemaa.iesp.uerj.br/levantamentos/evolucao-da-lei-no-12-711-nas-universidades-federais2015/>

FERES JÚNIOR, João; DAFLON, Verônica. et al. O impacto da Lei $\mathbf{n}^{0} \mathbf{1 2 . 7 1 1}$ sobre as universidades federais. Levantamento das políticas de ação afirmativa (GEMAA), IESP-UERJ, setembro, 2013. Disponível em< http://gemaa.iesp.uerj.br/levantamentos/o-impacto-da-lei-no-12711-sobre-as-universidades-federais-2013> 
GOMES, Joaquim B. Barbosa. O Debate Constitucional Sobre as Ações Afirmativas. 2001, Disponível em < http://www.egov.ufsc.br/portal/conteudo/o-debate-constitucional-sobrea\%C3\%A7\%C3\%B5es-afirmativas> acesso em : 18-07-2017.

IENSUE, Geziela. Política de cotas em universidades brasileiras: entre a legitimidade e a 2009.

Disponível em http://tede2.uepg.br/jspui/bitstream/prefix/284/1/Geziela\%20Iensue.pdf> acesso em 17 -10-2017.

Instituto de Pesquisa Econômica Aplicada - IPEA . Políticas sociais : acompanhamento e análise. V. $23-$ Brasília : Ipea, 2015. Disponível em < http://www.ipea.gov.br/portal/index.php?option=com_content $\&$ view=article\&id=25812\&Itemid=9 $>$

MENDONÇA, Marília Lima. SODRÉ, Nivia Cristina Miranda. et al. Ações Afirmativas e as Políticas de Cotas Raciais no Ensino. 2008.

MENEZES, Paulo Lucena de. Ação afirmativa (afirmative actiona) no direito norte-americano. São Paulo: Editora Revista dos Tribunais, 2001.

NOVELINO, Marcelo. Manual de Direito Constitucional. 9a Ed. rev. E atual. - Rio de Janeiro: Forense; São Paulo: Método, 2014.

PIOVESAN, Flavia. Ações Afirmativas da Perspectiva dos Direitos Humanos. Cad. Pesqui. [online]. 2005, vol.35, n.124, pp.43-55. ISSN. Disponível em: <http://www.scielo.br/scielo.php?pid=S010015742005000100004\&script=sci_abstract\&tlng=pt> acesso em 11-07-2017.

ROCHA, CÁRMEN LÚCIA ANTUNES Ação afirmativa: O conteúdo democrático do princípio da igualdade jurídica. Gênesis : Revista de Direito Administrativo Aplicado, v. 3, n. 10, p. 649-664, jul./set. 1996. Disponível em: <http://www2.senado.leg.br/bdsf/handle/id/176462> acesso em 1106-2017

VILAS-BÔAS, Renata Malta. Ações Afirmativas e o princípio da Igualdade. Rio de Janeiro: América Jurídica, 2003. 